\title{
Low- and high-dose fluticasone propionate in asthma; effects during and after treatment
}

\author{
N.H. Gershman*, H.H. Wong**, J.T. Liu**, J.V. Fahy***
}

Low- and high-dose fluticasone propionate in asthma; effects during and after treatment. N.H. Gershman, H.H. Wong, J.T. Liu, J.V. Fahy. (C)ERS Journals Ltd 2000.

ABSTRACT: The dose dependency of the effects of inhaled corticosteroids on markers of asthmatic airway inflammation have not been well studied. There is a need to study the dose/response effects on this inflammation.

In order to determine the dose/response effects of fluticasone propionate (FP), 24 asthmatic subjects were randomized to low- $\left(100 \mu \mathrm{g} \cdot \mathrm{day}^{-1}\right)$ or high-dose $\left(1,000 \mu \mathrm{g} \cdot \mathrm{day}^{-1}\right)$ FP for six weeks followed by placebo for 3 weeks.

During treatment, the median increase in forced expiratory volume in one second (FEV1) was $12 \%$ in the high-dose group $(p<0.05)$ and $10 \%$ in the low-dose group $(p<0.05)$ ( $>0.05$ between groups); the median decrease in the percentage of sputum eosinophils was $93 \%$ in the high-dose group $(p<0.05)$ and $46 \%$ in the low-dose group $(p<0.05)$ (p $>0.05$ between groups). Symptoms, salbutamol use, morning peak flow, provocative concentration of methacholine causing a $20 \%$ fall in FEV1 (PC20), sputum esinophil cationic protein concentration and tryptase activity improved significantly in both groups $(\mathbf{p}<\mathbf{0 . 0 5})$, but only the improvement in salbutamol use was greater in the highdose group $(p<0.05)$. During the run-out, the improvements in FEV1 and PC20 were rapidly reversed in both groups, but the improvements in peak flow and tryptase activity persisted; the improvement in sputum eosinophil concentration persisted only in the high-dose group $(p<0.05)$.

It was concluded that dose/response effects for FP are not easily demonstrable because low-dose FP is quite effective. For most outcomes, the effects of high- and lowdose FP are relatively short-lived after treatment is stopped. This finding raises questions about the extent to which inhaled corticosteroids are disease-modifying in asthma.

Eur Respir J 2000; 15: 11-18.
*Dept of Medicine and ${ }^{* *}$ Cardiovascular Research Institute, University of California, San Francisco, CA, USA

Correspondence: J.V. Fahy

Box 0111

University of California, San Francisco 505 Parnassus Avenue

San Francisco

CA 94143 USA.

Fax: 4154765712

\section{Keywords: Asthma}

dose

eosinophil

fluticasone propionate

response

tryptase

Received: October 51998

Accepted after revision September 281999

This study was supported by a research grant from GlaxoWellcome Inc.
Inhaled corticosteroids are the most effective treatment currently available for asthma [1]. The prevailing hypothesis regarding their efficacy is that they reduce airway inflammation and, in so doing normalize airway function and improve asthma control [2]. The coincidence of a reduction in airway eosinophilic inflammation and an improvement in asthma control in some studies of inhaled corticosteroids [3, 4] supports this hypothesis but does not prove it, since the association may not be causal in nature. In fact, the relationships between airway inflammation, airway function and response to treatment in asthma are poorly understood [5]. For example, it was recently found that treatment of asthmatic subjects with beclomethasone dipropionate at a low dose of $336 \mu \mathrm{g} \cdot \mathrm{day}^{-1}$ caused significant improvements in markers of asthma control but had only minimal effects on several markers of inflammation in induced sputum [6]. Other recent studies of inhaled corticosteroids have also found dissociations between the effects of inhaled steroids on airway function and their effects on various markers of airway inflammation [7-10]. In addition, it has been demonstrated that asthma control deteriorates within hours to days after inhaled cortico-

$\overline{\text { For editorial comments see page } 3}$ steroid treatment is stopped [6, 10-12]. This is surprising, since reducing airway inflammation is generally thought of as a disease-modifying action and, as such, would be expected to produce benefits that persist for some time after treatment is stopped. Finally, if one presumes that the prompt deterioration in asthma after inhaled corticosteroid treatment is stopped reflects the use of a dose inadequate to suppress inflammation, then it would have been expected that higher doses would have greater effects. Surprisingly, it has proven difficult to demonstrate a dose/response effect for inhaled corticosteroids on usual asthma outcome indicators such as forced expiratory volume in one second (FEV1) [13-17]; however, one study has reported the dose dependency of inhibition of exercise-induced bronchospasm [18] and another the dose dependency of prevention of asthma exacerbations [19]. To the authors' knowledge, no study has examined the dose dependency of the effects of inhaled corticosteroids on markers of inflammation in asthma nor on the duration of benefit after therapy is stopped.

The aim of this study was to explore further the relationship between airway inflammation and airway function in asthma by examining the dose/response effects of an inhaled corticosteroid, fluticasone propionate (FP), in asthmatic subjects. It was hypothesized that high-dose FP would 
cause a greater reduction in markers of airway inflammation than would low-dose FP and that this greater anti-inflammatory effect would translate to greater efficacy in asthma control both during treatment and after treatment is stopped. The specific research question addressed was whether highdose FP $\left(1,000 \mu \mathrm{g} \cdot\right.$ day $\left.^{-1}\right)$ is more effective than low-dose FP $\left(100 \mu \mathrm{g} \cdot \mathrm{day}^{-1}\right)$ in reducing airway inflam-mation, improving asthma control and providing longer-lasting benefit after treatment is stopped.

\section{Materials and methods}

\section{Subjects}

Twenty-four asthmatic subjects were studied (table 1); all were atopic except subject No.9. The inclusion criteria were a history of symptoms of asthma, an FEV $1 \leq 80 \%$ of the predicted value (or an FEV $1 \leq 85 \%$ pred and a forced mid-expiratory flow (FEF25-75\%) $<75 \%$ pred) and bronchial hyperreactivity to methacholine (provocative concentration of methacholine causing a $20 \%$ fall in FEV 1 $\left.(\mathrm{PC} 20) \leq 8 \mathrm{mg} \cdot \mathrm{mL}^{-1}\right)$. The exclusion criteria included a history of corticosteroid use (inhaled or oral) or an upper respiratory tract infection in the 6 weeks prior to study entry, tobacco use within the past year and a total smoking history of $>10$ pack-yrs. Subjects were recruited from advertisements placed in local newspapers or from a database of subjects who had previously participated in asthma studies at the authors' ${ }^{\prime}$ centre. The recruitment

Table 1. - Clinical characteristics of study subjects

\begin{tabular}{|c|c|c|c|c|}
\hline $\begin{array}{l}\text { Subject } \\
\text { No }\end{array}$ & $\begin{array}{l}\text { Age } \\
\text { yrs }\end{array}$ & Sex & $\begin{array}{l}\text { FEV1 } \\
\% \text { pred }\end{array}$ & $\begin{array}{c}\mathrm{PC} 20 \\
\mathrm{mg} \cdot \mathrm{mL}^{-1}\end{array}$ \\
\hline \multicolumn{5}{|c|}{ High-dose FP $\left(1,000 \mu g \cdot d^{-1}\right)$} \\
\hline 1 & 45 & $\mathrm{~F}$ & 70 & 0.29 \\
\hline 2 & 33 & M & 72 & 0.69 \\
\hline 3 & 52 & $\mathrm{M}$ & 80 & 1.31 \\
\hline 4 & 55 & $\mathrm{~F}$ & 71 & 3.30 \\
\hline 5 & 41 & $\mathrm{M}$ & 77 & 0.51 \\
\hline 6 & 31 & $\mathrm{M}$ & 58 & 0.34 \\
\hline 7 & 54 & $\mathrm{M}$ & 57 & 0.16 \\
\hline 8 & 32 & M & 59 & 0.16 \\
\hline 9 & 51 & M & 72 & 1.25 \\
\hline 10 & 35 & $\mathrm{M}$ & 70 & 0.77 \\
\hline 11 & 49 & $\mathrm{~F}$ & 62 & 0.10 \\
\hline 12 & 39 & M & 81 & 1.31 \\
\hline Mean & 43 & & 69 & $0.53 *$ \\
\hline \multicolumn{5}{|c|}{ Low-dose FP $\left(100 \mu \mathrm{g} \cdot \mathrm{day}^{-1}\right)$} \\
\hline 13 & 32 & $\mathrm{M}$ & 71 & 0.44 \\
\hline 14 & 26 & $\mathrm{M}$ & 75 & 0.23 \\
\hline 15 & 22 & M & 84 & 0.48 \\
\hline 16 & 42 & M & 67 & 0.31 \\
\hline 17 & 29 & M & 59 & 0.18 \\
\hline 18 & 32 & M & 59 & 0.18 \\
\hline 19 & 54 & M & 56 & 0.16 \\
\hline 20 & 48 & $\mathrm{M}$ & 76 & 0.36 \\
\hline 21 & 33 & $\mathrm{M}$ & 77 & 0.89 \\
\hline 22 & 26 & $\mathrm{M}$ & 65 & 0.20 \\
\hline 23 & 35 & $\mathrm{M}$ & 50 & 0.009 \\
\hline 24 & 32 & $\mathrm{M}$ & 52 & 0.53 \\
\hline Mean & 34 & & 66 & $0.28 *$ \\
\hline
\end{tabular}

*: geometric mean; FEV1: forced expiratory volume in one second; PC20: provocative concentration of methacholine causing a $20 \%$ fall in FEV1; FP: fluticasone propionate; F: female; M: male. strategy for the study did not include asking potential subjects to discontinue inhaled corticosteroid medications so that they could participate in the study. All subjects signed consent forms approved by the Committee on Human Research at the University of California, San Francisco.

\section{Protocol}

The study involved nine visits to the laboratory over an 11-week period. The study was a randomized doubleblind parallel-group study with a 2 week run-in, a 6 week double-blind treatment period with either $100 \mu \mathrm{g} \cdot \mathrm{day}^{-1}$ (low-dose) or 1,000 $\mu \mathrm{g} \cdot \mathrm{day}^{-1}$ (high-dose) FP, and a 3-week single-blind placebo run-out period (fig. 1).

\section{Study medication}

At the end of the 2-week run-in period (visit 2), subjects were randomized to receive one of two doses of inhaled FP in a single dummy design: the 24 drug packets used in the study were randomly assigned to contain either two 250 $\mu \mathrm{g} \cdot$ puff $^{-1}$ canisters of FP or one $50 \mu \mathrm{g} \cdot$ puff $^{-1}$ canister of FP and one "dummy" placebo canister. Drug packets were identified by number (1-24), and treatment assignment to subjects was determined by the order in which the subjects entered the treatment phase. The subjects were instructed to take one puff from each canister twice daily. Subjects were asked to use an Ellipse ${ }^{\mathrm{TM}}$ spacer device (Allen and Hanburys, Glaxo Inc., Durham, NC, USA), which has a volume of $200 \mathrm{~mL}$. At the first visit and each subsequent visit, subjects were observed during an inhalation manoeuvre in order to ensure adequate inhaler technique and instruction in proper technique was provided, if needed.

At the conclusion of the 6-week double-blind period (visit 5), the two double-blind drug canisters were replaced with identical placebo canisters which the subjects used for the remaining 3-week single-blind run-out period. Throughout the study, salbutamol inhalers were provided for symptomatic control of asthma symptoms, and the subjects were not permitted to use any other asthma medications.

\section{Rationale for selection of doses of fluticasone propi- onate}

Two doses of FP were compared, 100 and $1,000 \mu \mathrm{g} \cdot \mathrm{day}^{-1}$. The $100 \mu \mathrm{g} \cdot$ day $^{-1}$ dose is lower than that recommended in the package insert, but has been shown to improve FEV1 in subjects with mild and moderate asthma [13]. The 10-fold difference in dose was considered likely to reveal a dose/ response relationship were such a relationship easily demonstrable.

\section{Asthma symptoms}

During visit 1 subjects were taught how to complete a diary card which recorded asthma symptoms, rescue salbutamol use, nocturnal asthma awakenings and peak flow rates. The symptom component of the diary included daily self-assessments of shortness of breath, chest tightness, wheezing, cough and sputum production on a scale from 0 


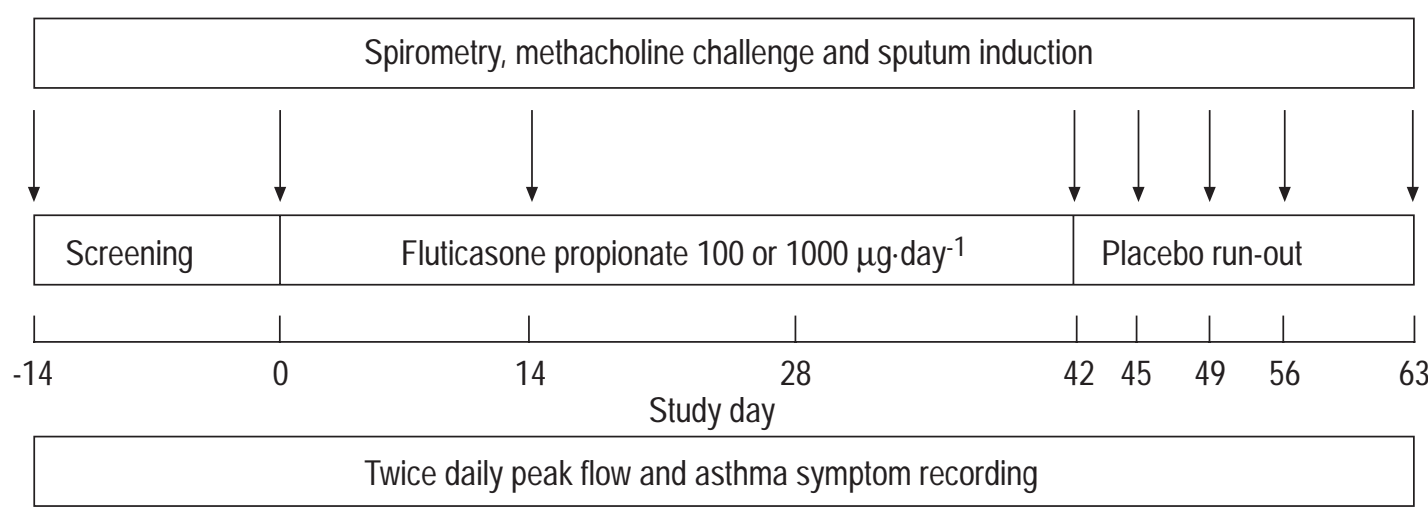

Fig. 1. - Diagrammatic representation of the 11-week randomized double-blind parallel group trial. On day 28 , spirometry and diary card review were carried out but methacholine challenge and sputum induction were not.

(none) to 10 (severe). The maximum possible daily score was $50(5 \times 10)$. The diary cards were reviewed and collected at all study visits.

\section{Peak flow}

During visit 1 , subjects were-instructed to record twice daily peak flow measurements using a MiniWright Peak Flow Meter (Clement Clarke, Columbus, OH, USA) and were asked to bring their peak flow meters to the laboratory at each visit for quality assessment with a flow/volume calibrating syringe (Jones, Inc., Oakbrook, IL, USA) using a previously described scheme for peak flow quality assurance [20]. Five peak flow meters, used by three subjects, failed relative bias or precision criteria during the study. In each case, the subject was provided with a new device of similar relative bias to use for the remainder of the study.

\section{Pulmonary function tests and allergen skin testing}

Bronchodilators were withheld for $8 \mathrm{~h}$ prior to testing. Spirometry, methacholine challenge and allergen skin testing were performed as previously described [6].

\section{Sputum induction}

All subjects were pretreated with $400 \mu \mathrm{g}$ salbutamol administered by means of a metered-dose inhaler, and spirometry was repeated $10 \mathrm{~min}$ later. All subjects had an FEV1 of $>60 \%$ pred following salbutamol pretreatment. Subjects then underwent standardized 20-min sputum induction as previously described [21]. Saliva collected during sputum induction was discarded and the induced sputum was processed as previously described [22]. The eosinophil cationic protein concentration (ECP) and tryptase activity in the induced sputum were determined in batched samples using commercially available radioimmunoassays (Pharmacia Diagnostics, Inc., Fairfield, NJ, USA). The lower limit of detection for the ECP assay was $2 \mathrm{ng} \cdot \mathrm{mL}^{-1}$; for the tryptase assay, the lower limit was 2 $\mathrm{IU} \cdot \mathrm{L}^{-1}$.

\section{Sample size calculation}

Data from two previous studies in the authors' laboratory guided the sample size calculation, which was based on estimated changes in sputum eosinophil percentage during treatment $[6,23]$. For the purposes of planning the study reported here, it was assumed that the effects of low-dose FP would be similar to the authors' previously documented effects of low-dose beclomethasone dipropionate [6] and that the effects of high-dose FP would be similar to the authors' previously documented effects of prednisone [23]. Using these assumptions, it was calculated that 12 subjects per arm would suffice to detect an effect size of $50 \%$ with a variability of this effect of $40 \%$ (standardized effect size 1.25, alpha 0.05, beta 0.8) [24].

\section{Statistics}

The baseline values were calculated as the means of the different parameters recorded during the 2-week run-in period (i.e. day 14 to day 0 ). For spirometric outcomes, the change from baseline was calculated based on the percentage change except for the FEV1 data expressed as a percentage of the predicted value, where absolute difference was used. For the $\mathrm{PC}_{20}$ data, the changes from baseline were calculated in terms of doubling concentrations. For sputum data, the change from baseline was calculated based on absolute differences. Within-group changes in outcome variables during the course of the study were compared using repeated-measures analysis of variance (or the equivalent nonparametric Friedman test if the data were not normally distributed). If a significant within-group difference was found using these tests, the paired t-test or the Wilcoxon signed-rank test, as appropriate, was used. Between-group changes (high- versus low-dose FP) in outcome variables were compared using the unpaired t-test or the Mann-Whitney U-test, as appropriate. Spearman's rankorder tests were used to determine correlations between data. A $p$-value of $<0.05$, using two-sided tests of significance, was considered significant.

\section{Results}

Baseline differences in FEV1, PC20, and morning peak flow between the groups were not statistically significant. 
All 12 subjects randomized to treatment with high-dose FP completed the study. Of the 12 subjects in the low-dose group, one (No.19) developed an upper respiratory infection during the last week of the run-out period which necessitated withdrawal from the study, and another subject (No.14) withdrew 3 days into the run-out period for personal reasons. Data on withdrawn subjects were included in the dataset until the time of withdrawal.

Pulmonary function, salbutamol use, and asthma symptoms

The mean FEV1, FEF25-75\% and morning peak flow rates increased significantly during the double-blind treatment period in both the high- and low-dose group (figs. 2 and 3 , table 2). The change from baseline in these pulmonary function parameters was not significantly different between the groups. The improvement in postsalbutamol FEV1 did not last long, however; it was not significantly greater than baseline 3 days after treatment was stopped (data not shown).

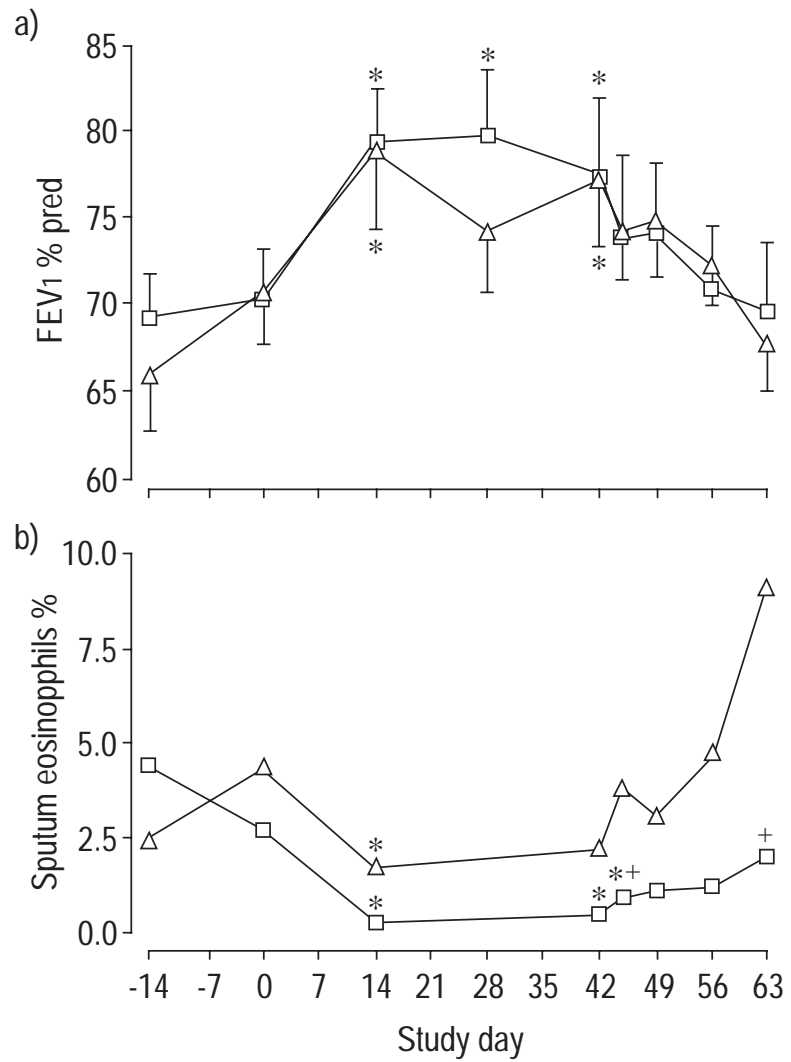

Fig. 2. - a) Forced expiratory volume in one second (FEV1, mean \pm SEM); and b) sputum eosinophil percentage (median) in the low- $\left(100 \mu \mathrm{g} \cdot \mathrm{day}^{-1}\right.$; $\triangle)$ and high-dose $\left(1,000 \mu \mathrm{g} \cdot \mathrm{day}^{-1} ; \square\right)$ fluticasone propionate (FP) groups during the two screening visits (days 14 and 0 ), the three visits while on double-blind (days 14, 28 and 42 (eosinophils not assayed on day 28), and the four visits of the placebo run-out phase (days 45, 49, 56 and 63). (Ranges of the sputum eosinophil percentages: low-dose FP: day $-14,0.4-27.4$; day $0,0.4-9.7$; day $14,0.0-4.4$; day $42,0.0-5.1$; day $45,0.4-10.0$; day 49, 0.0-15.6; day 56, 1.1-17.3; day 63, 0.7-32.6; and high-dose FP: day -14 , 0.0-45.7; day $0,0.0-29.6$; day 14, 0.0-9.4; day $42,0.0-15.5$; day $45,0.0-10.9$; day $49,0.0-10.5$; day $56,0.0-7.3$; day $63,0.0-12.2$.) *: $\mathrm{p}<0.05$ versus baseline (mean of day -14 and day 0$){ }^{+}$: $\mathrm{p}<0.05$ versus change from baseline in low-dose group.
The $\mathrm{PC} 20$ increased significantly (i.e. bronchial reactivity to methacholine decreased) during the double-blind treatment period in both groups (table 2), but the change in the high-dose FP group after 42 days of treatment (median increase of 1.5 doubling concentrations) was not significantly different from that in the low-dose FP group (increase of 1.3 doubling concentrations; $p=0.95$ at 6 weeks) (table 2).
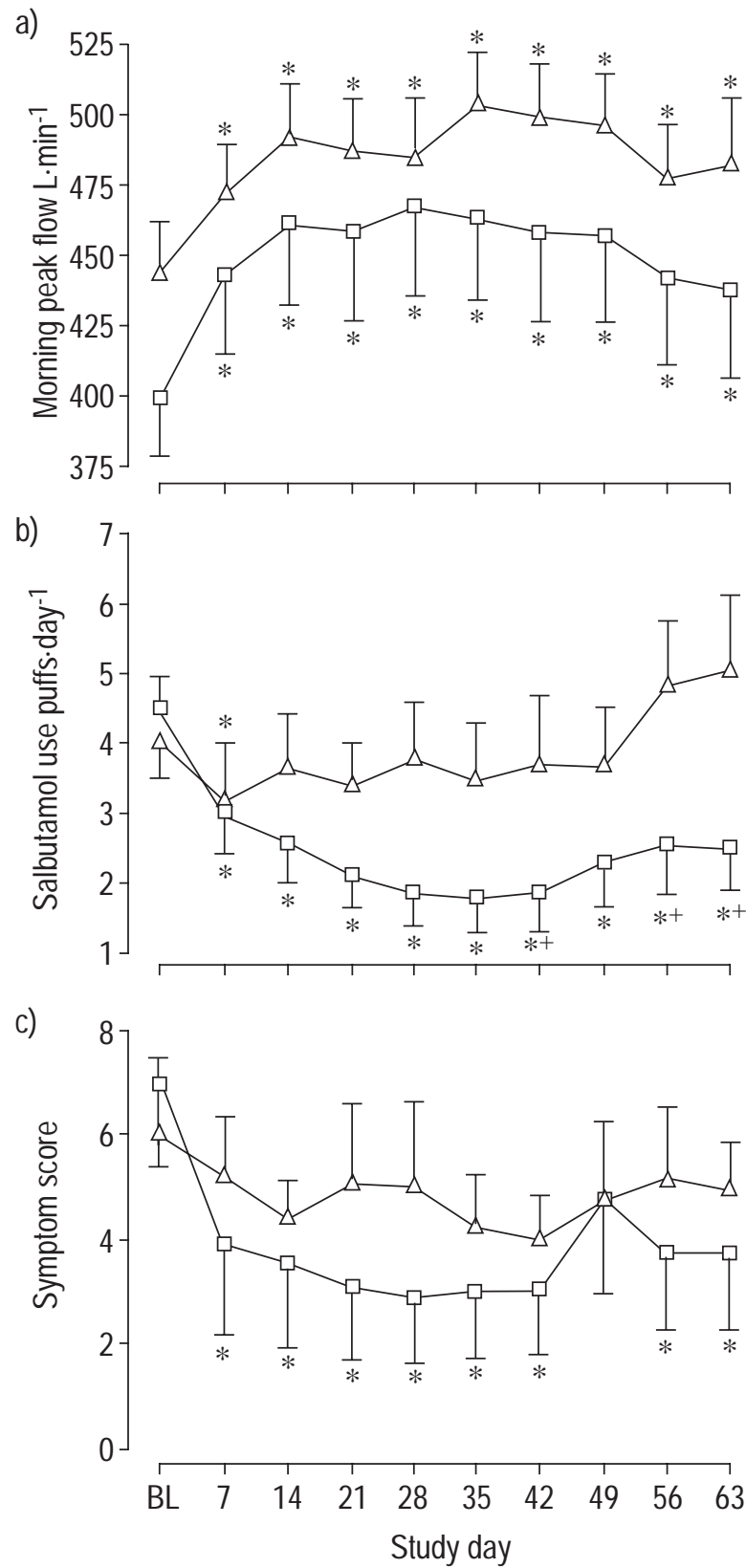

Fig. 3. - a) Morning peak flow; b) salbutamol use; and c) composite symptom score in the low- $\left(100 \mu \mathrm{g} \cdot \mathrm{day}^{-1} ; \triangle\right)$ and high-dose $(1,000$ $\left.\mu \mathrm{g} \cdot \mathrm{day}^{-1} ; \square\right)$ fluticasone propionate (FP) (BL; mean data from the 2week run-in period), during double-blind treatment (days 1-42) and during the placebo run-out phase (days 43-63). Data are presented as mean \pm SEM and salbutamol use as the mean from a 1-week period. There was a strong trend for a decrease in asthma symptoms in the low-dose group during treatment $(\mathrm{p}=0.051$ at day 42$){ }^{*}: \mathrm{p}<0.05$ versus baseline; ${ }^{+}$: $\mathrm{p}<0.05$ versus change from baseline in low-dose FP group. 
Table 2. - Comparison of effect of fluticasone propionate (FP) at low and high dose on asthma control outcomes and markers of inflammation in induced sputum

\begin{tabular}{|c|c|c|c|c|c|c|c|c|c|}
\hline \multirow[t]{2}{*}{ Screening day } & \multirow[b]{2}{*}{-14} & \multirow[b]{2}{*}{0} & \multicolumn{3}{|c|}{ Treatment day } & \multicolumn{4}{|c|}{ Placebo run-out day } \\
\hline & & & 14 & 28 & 42 & 45 & 49 & 56 & 63 \\
\hline \multicolumn{10}{|c|}{ Low-dose FP $\left(100 \mu \mathrm{g} \cdot \mathrm{day}^{-1}\right)$} \\
\hline FEV1 L & $2.63 \pm 0.17$ & $2.84 \pm 0.19$ & $3.21 \pm 0.22 *$ & $2.95 \pm 0.18$ & $3.09 \pm 0.22 *$ & $2.95 \pm 0.14$ & $2.98 \pm 0.18$ & $2.87 \pm 0.17$ & $2.72 \pm 0.16$ \\
\hline FEF $25-75 \% \mathrm{~L} \cdot \mathrm{min}^{-1}$ & $1.62 \pm 0.19$ & $1.79 \pm 0.23$ & $2.18 \pm 0.22 *$ & $1.93 \pm 0.16$ & $2.07 \pm 0.24 *$ & $2.02 \pm 0.18$ & $1.97 \pm 0.18$ & $1.83 \pm 0.19$ & $1.74 \pm 0.18$ \\
\hline \multirow[t]{2}{*}{$\mathrm{PC} 20 \mathrm{mg} \cdot \mathrm{mL}^{-1}$} & 0.27 & 0.43 & 0.63 & & 0.71 & 0.33 & 0.49 & 0.40 & 0.36 \\
\hline & $(0.1-0.9)$ & $(0.2-2.9)$ & $(0.3-2.5)^{*}$ & ND & $(0.2-10.0)^{*}$ & $(0.1-1.3)$ & $(0.2-1.6)$ & $(0.2-1.5)$ & $(0.2-1.5)$ \\
\hline $\mathrm{ECP} \mathrm{ng} \cdot \mathrm{mL}^{-1}$ & $\begin{array}{c}172 \\
(23-758)\end{array}$ & $\begin{array}{c}227 \\
(27-1790)\end{array}$ & $\begin{array}{c}154 \\
(24-282)^{*}\end{array}$ & ND & $\begin{array}{c}139 \\
(50-529)\end{array}$ & $\begin{array}{c}200 \\
(62-732)\end{array}$ & $\begin{array}{c}222 \\
(42-742)\end{array}$ & $\begin{array}{c}232 \\
(40-1470)\end{array}$ & $\begin{array}{c}200 \\
(77-2864)\end{array}$ \\
\hline \multicolumn{10}{|c|}{ High-dose FP $\left(1,000 \mu \mathrm{g} \cdot\right.$ day $\left.^{-1}\right)$} \\
\hline FEV1 L & $2.35 \pm 0.14$ & $2.43 \pm 0.17$ & $2.75 \pm 0.18^{*}$ & $2.73 \pm 0.18^{*}$ & $2.75 \pm 0.20^{*}$ & $2.57 \pm$ & $2.57 \pm 0.20$ & $2.44 \pm 0.18$ & $2.40 \pm 0.18$ \\
\hline FEF $25-75 \% \mathrm{~L} \cdot \mathrm{min}^{-1}$ & $1.46 \pm 0.16$ & $1.54 \pm 0.17$ & $1.87 \pm 0.17$ & $1.89 \pm 0.13 *$ & $1.86 \pm 0.15^{*}$ & $1.72 \pm 0.15$ & $1.70 \pm 0.16$ & $1.59 \pm 0.14$ & $1.55 \pm 0.15$ \\
\hline \multirow[t]{2}{*}{$\mathrm{PC} 20 \mathrm{mg} \cdot \mathrm{mL}^{-1}$} & 061 & 038 & 0.95 & & 0.90 & 0.7 & 0.90 & 0.35 & 0.4 \\
\hline & $(0.1-3.3)$ & $(0.1-2.4)$ & $(0.1-11.2)^{*}$ & ND & $(0.1-5.4)^{*}$ & $(0.1-5.5)^{*}$ & $(0.2-12.0)^{*}$ & $(0.1-3.5)$ & $(0.1-2.3)$ \\
\hline \multirow[t]{2}{*}{$\mathrm{ECP} \mathrm{ng} \cdot \mathrm{mL}^{-1}$} & 149 & 147 & 84 & & 86 & 112 & 128 & 88 & 122 \\
\hline & $(35-702)$ & $(27-344)$ & $(24-165)^{*}$ & ND & $(26-306)$ & $(38-299)$ & $(33-498)$ & $(14-352)$ & $(59-477)$ \\
\hline
\end{tabular}

Data are presented as mean \pm SEM, geometric mean (range) (provocative concentration of methacholine causing a $20 \%$ fall in forced expiratory volume in one second (FEV1) (PC20)) or median (range) (eosinophil cationic protein (ECP)). FEF25-75: forced midexpiratory flow; ND: no determined. *: $\mathrm{p}<0.05$ versus baseline (mean of day -14 and day 0 ).

The frequency of rescue salbutamol inhalations decreased significantly during the double-blind treatment period in both the high- and low-dose group (fig. 3) (at week 1 only in the low-dose group and at all time points in the high-dose group), but decreased significantly more in the high-dose group than in the low dose group ( $\mathrm{p}=0.049$, between groups). The asthma symptom score decreased significantly during treatment in the high-dose FP group $(\mathrm{p}=0.037)$, and there was a strong trend toward improvement in the low-dose FP group $(\mathrm{p}=0.051)$. However, the change in asthma symptom score during treatment in the two groups was not significantly different (fig. 3) $(\mathrm{p}=$ 0.34 , between groups).

The treatment-associated improvements in spirometric values and methacholine reactivity were short-lived; the improvements in these outcomes largely reversed 3-7 days after double-blind treatment was stopped (figs. 2 and 3, table 2). In contrast, the improvements in peak flow persisted for 3 weeks after therapy in both groups, as did improvements in symptom score and salbutamol usage in the high-dose group. The between-group differences in the time course of reversal of improvement in rescue salbutamol use were statistically significant, but none of the other between-group differences were statistically significant.

\section{Markers of inflammation in induced sputum}

The percentage of eosinophils in induced sputum decreased significantly after 14 days of treatment in both treatment groups; the percentage of eosinophil remained significantly lower than baseline only in the high-dose FP group after 42 days of treatment (fig. 2). In the high-dose FP group the median value for the change in sputum eosinophil percentage from baseline to the end of the double-blind treatment was $93 \%$; seven of the 12 subjects experienced a $>90 \%$ reduction and eight a $>50 \%$ reduction. In the low-dose FP group, the median value for the change in sputum eosinophil from baseline to the end of the double-blind treatment was $46 \%$; three of the 12 subjects showed a $>90 \%$ reduction and six a $>50 \%$ reduction. The changes in sputum eosinophil percentage from baseline to 14 and 42 days of treatment did not differ significantly between the two groups ( $>0.05$ for both time points).

The levels of ECP in induced sputum decreased significantly during the double-blind treatment period in both the high- and low-dose groups (table 2), but the change between groups was not significantly different. The decrease in ECP concentration was $37 \%$ from baseline to the end of the double-blind treatment in the high-dose group and $41 \%$ in the low-dose group. Similarly, the tryptase activity of induced sputum decreased significantly during the double-blind treatment period in both the highand low-dose groups (fig. 4), but the change was not significantly different between groups. The decrease in tryptase activity was $85 \%$ from baseline to the end of the double-blind treatment in the high-dose group and $57 \%$ in the low-dose group.

The treatment-associated improvement in sputum eosinophil percentage in the high-dose FP group was more persistent than that in the low-dose FP group, i.e. the highdose group showed a significantly greater suppression of sputum eosinophil percentage after treatment was stopped than did the low dose group (fig. 2). In contrast, there was no significant between-group difference in the persistence of the treatment-associated reductions in ECP concentration after treatment was stopped. The treatment-associated improvement in sputum tryptase activity persisted in both the low- and high-dose FP groups after treatment was stopped; the change in sputum tryptase activity from baseline to the run-out visits was not significantly different between groups (fig. 4).

\section{Correlations}

In all 24 subjects, the change in FEV1 from baseline to day 42 was significantly correlated with the change in 

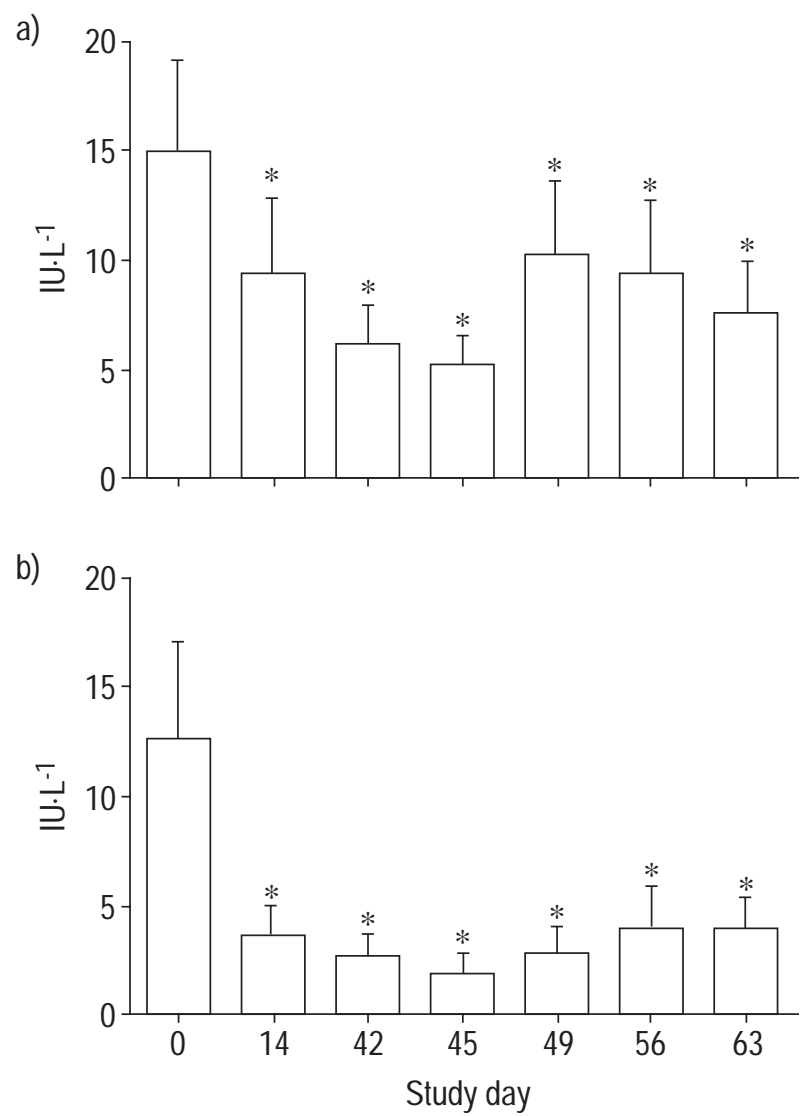

Fig. 4. - Tryptase activity in induced sputum at baseline (mean of day 14 and day 0 ), during treatment (days 14 and 42) and during the run-out phase (days 45, 49, 56 and 63) in: a) the low-dose fluticasone propionate (FP) group $\left(100 \mu \mathrm{g} \cdot \mathrm{day}^{-1}\right)$; and $\left.\mathrm{b}\right)$ the high-dose FP group $(1,000$ $\left.\mu \mathrm{g} \cdot \mathrm{day}^{-1}\right){ }^{*}: \mathrm{p}<0.05$ versus baseline. None of the changes from baseline in the high-dose group were significantly different from those found in the low-dose group.

sputum eosinophil ( $\mathrm{rs}=0.45, \mathrm{p}=0.032)$ and with the change in sputum ECP concentration ( $\mathrm{rs}=0.67, \mathrm{p}=0.001$ ). In contrast, the change in FEV1 from baseline to day 42 was not significantly correlated with sputum tryptase activity $(\mathrm{rs}=0.104, \mathrm{p}=0.62)$.

\section{Discussion}

The main findings of the present study are that dose/ response effects of FP on outcomes including FEV1, PC20 and sputum eosinophilia are not easily demonstrable in moderate asthma, largely because low-dose FP is quite effective, and that treatment-associated improvements reverse quite quickly in both the low- and high-dose groups.

A variety of outcome indicators of asthma control were examined, including FEV1, peak flow, methacholine reactivity, asthma symptom score and rescue salbutamol use. Both low- and high-dose FP treatment resulted in statistically significant improvements from baseline during the treatment phase in most of these outcomes. For example, the FEV 1 and morning peak flow increased from baseline by $\sim 15 \%$ following 6 weeks of treatment in both groups, and the PC20 increased by $\sim 1$ doubling concentration in both groups. The high-dose group had greater reductions in rescue salbutamol use than did the low-dose group, even though the effects of the two treatment regimens on asthma symptom score were not significantly different. Overall, these findings indicate that dose/response effects of FP on usual measures of asthma control are not easy to demonstrate. These findings are consistent with those reported previously in other studies $[13,14,16]$; only when large numbers of subjects are studied is it possible to find a dose/ response effect of inhaled corticosteroids on FEV1 [19, 25, 26].

The present study examined asthma control outcomes not only during 6 weeks of treatment with low- and highdose FP ("on treatment effect") but also during the 3 weeks after treatment was stopped ("off treatment effect"). It was reasoned that dose/response effects might be more easily demonstrable for the off-treatment effects because greater anti-inflammatory effects of FP might translate to a more persistent benefit after treatment cessation. Surprisingly, the off-treatment effects of low- and high-dose FP were similar for most clinical outcomes. The only clinical outcome for which there was a dose/response effect of the higher dose during the off-treatment period was rescue salbutamol use. Neither dose of FP had a significant offtreatment effect on FEV1; the FEV1 was no longer significantly greater than baseline in either group 3 days after treatment cessation and the improvement in FEV1 was nearly completely reversed within 2 weeks of treatment cessation. The short off-treatment effect of inhaled corticosteroids on FEV1 has been noted previously [10-12], although the authors believe that this study is the first to examine dose/response effects on this outcome variable. Both doses of FP had persistent effects on morning peak flow, with significant improvements compared to baseline noted 3 weeks after treatment cessation in both groups. Thus, the off-treatment effects of FP on peak flow and FEV1 were dissociated, perhaps reflecting greater effects on the large central airways (reflected in the peak flow measurement) than in the more peripheral airways (reflected in the FEV1 measurement).

Although no statistically significant difference for the off-treatment effect of FP on methacholine reactivity was found, the improvement in $\mathrm{PC} 20$ in the high-dose group was sustained for 2 weeks, whereas it was reversed in the low-dose group within 3 days.

The effects of low- and high-dose FP on eosinophil percentage, ECP concentration and tryptase activity in induced sputum were examined. It was found that highdose FP was associated with a larger reduction in sputum eosinophil percentage than was low-dose FP, but this between-group difference was not significant. The offtreatment effect of high-dose FP on sputum eosinophil percentage was significantly greater than the off-treatment effect of low-dose FP. Thus, sputum eosinophil percentage represented an outcome for which a dose/response effect was not evident during treatment but became evident after treatment was stopped. The reductions in sputum ECP concentration associated with low-dose and high-dose FP were not as great as the effects on sputum eosinophil percentage. Both low-dose and high-dose FP were associated with a significant within-group reduction in sputum tryptase activity, which persisted in both groups for the entire 3 week off-treatment period. 
Two assumptions were made in predicting that 12 asthmatic subjects per arm would provide sufficient power to detect dose/response effects of FP on sputum eosinophil percentage. First, it was assumed that the effects of 6 weeks of treatment with FP 1,000 $\mu \mathrm{g} \cdot \mathrm{day}^{-1}$ on sputum eosinophil percentage would be as great as those previously observed with 6 days of prednisone $0.5 \mathrm{mg} \cdot \mathrm{kg} \cdot \mathrm{day}^{-1}$ [23]. Secondly, it was assumed that the effects of 6 weeks of treatment with FP $100 \mu \mathrm{g} \cdot \mathrm{day}^{-1}$ would be as small as the effects previously observed with 4 weeks of beclomethasone dipropionate $336 \mu \mathrm{g} \cdot \mathrm{day}^{-1}$ [6]. The first of these assumption proved correct, but the effects of FP $100 \mu \mathrm{g} \cdot \mathrm{day}^{-1}$ on sputum eosinophil percentage proved greater and more variable than those previously observed with beclomethasone dipropionate $336 \mu \mathrm{g} \cdot \mathrm{day}^{-1}[6]$. The data for the change in sputum eosinophil percentage in the current study were affected by the fact that five subjects in the high-dose group and four in the low-dose group had a low percentage of sputum eosinophils $(<2 \%)$ in their induced sputum at baseline. This finding suggests that subjects should be screened for the presence of sputum eosinophilia $(>2 \%)$ as an eligibility criterion for studies that examine sputum eosinophil percentage as an outcome. Such an approach was considered for this study but decided against on the reasoning that sputum ECP concentration was an additional outcome that could be evaluated in subjects with low sputum eosinophil percentage. However, in this and other studies $[6,23]$, the sputum ECP concentration has proven less sensitive to change than the sputum eosinophil percentage.

In examining the relationships between the effects of low- and high-dose FP on markers of airway inflammation and on asthma control outcomes during the off-treatment period, it is dear that the persistent effects or otherwise of either high- or low-dose FP on sputum eosinophil percentage or sputum tryptase activity were not always mirrored by their persistent effects on other asthma control outcomes. For example, although a sustained reduction in sputum eosinophil percentage during the off-treatment period in the high-dose treatment group was associated with a sustained reduction in rescue salbutamol requirements, this sustained reduction in sputum eosinophil percentage was not associated with any significant sustained improvements in FEV1 or methacholine reactivity. In addition, although no sustained reduction in sputum eosinophil percentage was observed during the off-treatment period in the low-dose treatment group, this group nevertheless showed sustained improvements in peak flow similar to the improvement observed in the high-dose treatment group. Furthermore, although the on-treatment reduction in sputum tryptase activity was sustained during the off-treatment period in both treatment groups, this persistent reduction was not associated with persistent effects on any asthma control outcomes except peak flow (both groups) and salbutamol use (high-dose group only) during the offtreatment period. These observations serve to emphasize that the relationship between these markers of airway inflammation and airway function in moderate asthma is complex, and that the relationship differs depending on the outcome studied. An important outcome not studied in this clinical trial was asthma exacerbation rate, which is an outcome that often drives dosing regimens of inhaled corticosteroids and that may be more closely related to airway inflammation than some of the outcomes measured in the present study.

In summary, it was found that both low- and high-dose fluticasone propionate improved most outcomes of asthma control during treatment but that dose/response effects were difficult to demonstrate because low-dose fluticasone propionate was quite effective. Dissociations between effects of treatment on markers of inflammation and on asthma control outcomes were evident, most notably during the off-treatment period. It was concluded that the relationship between airway inflammation, airway function and asthma symptoms is complex. In addition, the rapidity of the offtreatment effect for most asthma control outcomes in both the low- and high-dose groups raises questions about the extent to which inhaled corticosteroids, even in high-doses, are disease-modifying in asthma.

\section{References}

1. Barnes PJ. Inhaled glucocorticoids for asthma. New Engl $J$ Med 1995; 332: 868-873.

2. Barnes PJ, Pedersen S, Busse WW. Efficacy and safety of inhaled corticosteroids; New developments. Am J Respir Crit Care Med 1998; 157: S1-S53.

3. Laitinen L, Laitinen A, Haahtela T. A comparative study of the effects of an inhaled corticosteroid, budesonide, and a $\beta_{2}$-agonist, terbutaline, on airway inflammation in newly diagnosed asthma: A randomized, double-blind, parallel-group controlled trial. J Allergy Clin Immunol 1992; 90: 32-42.

4. Djukanovic R, Wilson JW, Britten KM, et al. Effect of an inhaled corticosteroid on airway inflammation and symptoms in asthma. Am Rev Respir Dis 1992; 145: 669-674.

5. Haley KJ, Drazen JM. Inflammation and airway function in asthma. What you see is not necessarily what you get. Am J Respir Crit Care Med 1998; 157: 1-3.

6. Fahy JV, Boushey HA. Effect of low dose beclomethasone dipropionate on asthma control and airway inflammation. Eur Respir J 1998; 11: 1240-1247.

7. Adelroth E, Rosenhall L, Johansson SA, Linden M, Venge P. Inflammatory cells and eosinophilic activity in asthmatics investigated by bronchoalveolar lavage. $\mathrm{Am}$ Rev Respir Dis 1990; 142: 91-99.

8. Booth H, Richmond I, Ward C, Gardiner PV, Harkawat R, Walters EH. Effect of high dose inhaled fluticasone propionate on airway inflammation in asthma. $\mathrm{Am} \mathrm{J}$ Respir Crit Care Med 1995; 152: 45-52.

9. Trigg CJ, Manolitsas ND, Wang J, et al. Placebo controlled immunopathologic study of four months of inhaled corticosteroids in asthma. Am J Respir Crit Care Med 1994; 150: 17-22.

10. Woolcock A, Lundback B, Ringhal OLN, Jacques LA. Comparison of addition of salmeterol to inhaled steroids with doubling of the dose of inhaled steroids. Am J Respir Crit Care Med 1996; 153: 1481-1488.

11. Vathenen AS, Knox AJ, Wisniewski A, Tattersfield AK. Time course of change in bronchial reactivity with an inhaled corticosteroid in asthma. Am Rev Respir Dis 1991; 143: 1317-1321.

12. Bel EH, Timmers MC, Hermans J, Dijkman JH, Sterk PJ. The long-term effects of nedocromil sodium and beclomethasone dipropionate on bronchial responsiveness to methacholine in nonatopic asthmatic subjects. Am Rev Respir Dis 1990; 141: 21-28.

13. Chervinsky P, Van As A, Bronsky EA, et al. Fluticasone 
propionate aerosol for the treatment of adults with mild to moderate asthma. J Allergy Clin Immunol 1994; 94: 676683.

14. Wolfe JD, Selner JC, Mendelson LU, Hampel F, Schaberg A. Effectiveness of fluticasone propionate in patients with moderate asthma: a dose ranging study. Clin Ther 1996; 4: 635-646.

15. Welch MJ, Levy S, Smith JA, Feiss G, Farrar JR. Dose ranging study of the clinical efficacy of twice daily triamcinolone acetonide inhlalation aerosol in moderately severe asthma. Chest 1997; 112: 597-606.

16. Wasserman SI, Gross GN, Schoenwetter WF, et al. A 12 week dose ranging study of fluticasone propionate powder in the treatment of asthma. J Asthma 1996; 33: 265-274.

17. Gaddie J, Reid IW, Skinner C, Petrie GR, Sinclair DJM, Palmer KNV. Aerosol beclomethasone dipropionate: a dose response study in chronic bronchial asthma. Lancet 1973; i: 691-693.

18. Pedersen S, Hansen OR. Budesonide treatment of moderate and severe asthma in children: A dose-response study. J Allergy Clin Immunol 1995; 95: 29-33.

19. Pauwels RA, Lofdahl C-G, Postma DS, et al. Effect of inhaled formoterol and budesonide on exacerbations of asthma. N Eng J Med 1997; 337: 1405-1411.

20. Irvin CG, Martin RJ, Chinchilli VM, Kunselman SJ,
Cherniack RM. Quality control of peak flow meters for multicenter clinical trials. Am J Respir Crit Care Med 1997; 156: 396-402.

21. Gershman NH, Wong HH, Liu JT, Mahimeister MJ, Fahy JV. Comparison of two methods of collecting induced sputum in asthmatic subjects. Eur Respir $J$ 1996; 9: 2448-2453.

22. Fahy JV, Liu J, Wong H, Boushey HA. Cellular and biochemical analysis of induced sputum from asthmatic and from healthy subjects. Am Rev Respir Dis 1993; 147: $1126-1131$.

23. Claman D, Boushey HA, Liu J, Wong H, Fahy JV. Analysis of induced sputum to examine the effects of prednisone on airway inflammation. J Allergy Clin Immunol 1994; 94: 861-869.

24. Glantz S. Primer of Biostatistics Software, Version 3.0. New York, St Louis, San Francisco, McGraw Hill, 1992; pp. 155-187.

25. Mullen B, Sykes J. Dose response effects in the treatment of asthma with fluticasone propionate: a meta-analytic integration. Am J Respir Crit Care Med 1998; 157: A408.

26. Nathan RA, Nolop KB, Cuss FM, Lorber RR. A comparison of double strength beclomethasone dipropionate ( 84 $\mu \mathrm{g})$ MDI with beclomethasone dipropionate $(42 \mu \mathrm{g})$ in the treatment of asthma. Chest 1997; 112: 34-39. 